\title{
Penerapan Model Pembelajaran Inkuiri tipe 5E berbasis Scaffolding sebagai Transfer Tanggung Jawab Kelas VIII di SMPN 1 Kota Jambi
}

\author{
Desi Puspita Sari, Muhammad Rusdi, Evita Anggereini \\ Program Studi Magister Pendidikan IPA Universitas Jambi \\ Email: desips205@gmail.com
}

DOI: https://doi.org/10.33369/pendipa.5.3.359-365

\begin{abstract}
The aim of this research was to find out whether instructional scaffolding should be provided by the teacher to support the students in mastering several learning techniques in accordance to the learning model used. This instructional scaffolding can be employed through verbal (language development focused), procedural (grouping technique and activity structure and frames), and tools that support learning. It can be given after dynamics assessment in the classroom. This research was conducted by preparing procedural scaffolding in the form of worksheets and implemented in the classroom to obtain the dynamics of fading and transfer of responsibility using the 5E Inquiry-Based Instructional Model: Engage, Explore, Explain, Elaborate, and Evaluate. This classroom action research takes place in three cycles. Each cycle goes through the stages of planning, action, observation and reflection. The data of this research is collected through observation sheets and the designed worksheets to assess their group discussion skills using the 5E Inquiry-Based Instructional Model. The results showed that there was a transfer of responsibility from the teacher to students. In the end, by providing high-quality instructions, it allows the students to do their job properly.
\end{abstract}

Keywords: Transfer of responsibility, Scaffolding, Inquiry learning model type $5 E$.

\begin{abstract}
ABSTRAK
Penelitian tentang scaffolding ini bertujuan untuk mengetahui bantuan apa yang tepat diberikan guru kepada peserta didik dalam menguasai beberapa teknik belajar yang sesuai dengan model pembelajaran yang digunakan. Scaffolding dapat berbentuk verbal (language development focused), prosedural (grouping technique and activity structure and frames), dan berbentuk tools (tools that support learning). Scaffolding dapat diberikan setelah melakukan dynamics assessment di kelas. Penelitian ini dilakukan dengan mempersiapkan scaffolding procedural dalam bentuk LKPD dan dipraktekkan di kelas dalam pembelajaran untuk mendapatkan dinamika fading dan transfer tanggung jawab komponen aktivitas pembelajaran dengan menggunakan model pembelajaran inkuiri tipe 5E yaitu Engage, Explore, Explain, Elaborate, dan Evaluate. Penelitian ini merupakan penelitian tindakan kelas yang berlangsung secara tiga siklus. Tiap siklus melalui tahap perencanaan tindakan, pelaksanaan tindakan, observasi dan refleksi. Jenis data dalam penelitian ini berupa data tindakan guru dan tindakan siswa dalam bentuk lembar observasi dan data penilaian keterampilan diskusi kelompok dengan tahapan 5E melalui LKPD yang telah dirancang. Hasil penelitian menunjukkan adanya transfer tanggung jawab dari guru ke peserta didik. Pada akhirnya, dengan memberikan instruksi yang berkualitas, memungkinkan peserta didik untuk melaksanakan tugasnya sebagai siswa dengan baik.
\end{abstract}

Kata kunci: Transfer Tanggung Jawab, Scaffolding, Model Pembelajaran Inkuiri tipe 5E. 


\section{PENDAHULUAN}

Pembelajaran pembelajaran

sains

merupakan yang popular mempergunakan pendekatan proses. Hasil penelitian pendekatan proses telah menjadi acuan bagi pembelajaran bidang ilmu lainnya dalam mengembangkan proses pembelajaran bidang ilmunya masingmasing. Pendekatan proses dalam pembelajaran sains pada dasarnya menggunakan prinsip eklektisme dengan memadukan paradigma belajar behavioristik, kognitivistik dan konstruktivisme. Ketiga paradigma tersebut saling melengkapi dan menyempurnakan. Secara teknis, prinsip pragmatism pendidik dapat merekayasa komponen yang terdapat pada setiap paradigma untuk dijadikan sajian baru dalam pembelajarannya.

Berkaitan dengan pendekatan proses, tujuan pembelajaran yang diinginkan adalah meningkatkan keterampilan peserta didik dalam belajar. Dalam proses pembelajaran terdapat tiga komponen penting yaitu pendidik membelajarkan peserta didik, peserta didik belajar untuk meningkatkan keterampilan belajarnya dan hasil belajar yang hubungan dengan materi pembelajaran. Diskusi pada penelitian ini akan mendeskripsikan dua komponen pertama, dimana keduanya selalu terjadi di kelas dalam bentuk interaksi belajar mengajar. Prinsip interaksi antara pendidik dengan peserta didik merupakan kegiatan pengalihan tanggung jawab (transfer of responsibility). Pengalihan tanggung jawab tersebut dilakukan dalam konteks melatih keterampilan belajar yang sesuai dengan alur pembelajaran yang direncanakan oleh pendidik. Proses pengalihan tanggung jawab tersebut membutuhkan bantuan (scaffolding) yang dapat menyempurnakan tindakan belajar dari peserta didik. Scaffolding dapat diberikan oleh pendidik, tutor, alat bantu berbasis teknologi, ahli ataupun sesama peserta didik.

Penelitian tentang scaffolding dilakukan baik dalam perspektif mendesain konsep (Quintana, et al., 2004), mengujicobakan proses (Reigosa, \& Jiménez-Aleixandre, 2007) dan melihat dampak yang dihasilkan (Molenaar, I., van Boxtel, \& Sleegers 2011). Disamping itu juga terdapat penelitian yang mendeskripsikan profile fading yang diberikan pada proses scaffolding (van de Pol, Volman, \& Beishuizen, 2010). Penelitian-penelitian tersebut merupakan rangkaian yang baik untuk melakukan kajian yang lengkap tentang scaffolding. Mengujicobakan proses scaffolding merupakan kajian yang dinamis, karena secara practical berpotensi untuk berbeda dari satu kondisi dengan kondisi lainnya. Fading merupakan kecenderungan berkurangnya scaffolding yang diberikan oleh pendidik kepada peserta didik. Dinamika fading pada scaffolding dapat berbeda antara satu siswa dengan siswa lainnya, oleh karena itu dinamika fading scaffolding yang diberikan oleh guru dapat memberikan profile yang menarik sebagai refleksi terhadap transfer tanggung jawab yang sudah diperoleh oleh peserta didik.

Berdasarkan studi pendahuluan yang dilakukan pada peserta didik kelas VIII di SMP Negeri 1 Kota Jambi, sebagian besar peserta didik belum dapat mandiri dalam memecahkan masalah pada diskusi kelompok. Peserta didik hanya bergantung pada guru dan percaya sepenuhnya segala informasi harus didapat dari pendidik. Hal tersebut menimbulkan tanggung jawab sepenuhnya dipegang oleh guru bukan peserta didik. Selain itu, terdapat peserta didik pasif yang hanya menunggu jawaban dari teman dan interaksi antar dalam kelompok masih kurang. Hal ini menyebabkan guru yang lebih aktif di kelas dengan membimbing penuh setiap kelompok diskusi yang ingin bertanya kemudian menjawab pertanyaan yang peserta didik ajukan. Pertanyaan tersebut seharusnya dipecahkan sendiri oleh peserta didik bukan guru.

Model Inkuiri tipe 5E merupakan model yang sebelumnya direkonstruksi 
oleh peneliti dengan berbagai teori pendukung sebagai penguat rekonstruksi model. Model ini merupakan kombinasi dari model inkuiri dan model 5E (Engage, Explore, Explain, Elaborate dan Evaluate). Menurut Shoimin (2014:85) mengemukakan model pembelajaran inkuiri merupakan model pembelajaran yang lebih mengutamakan keaktifan peserta didik dalam menemukan konsepkonsep berdasarkan masalah yang diajukan sehingga dapat dijadikan sebagai pengalaman belajar. Menurut Contant dkk (2018:97) model 5E juga memfasilitasi penerapan faktor-faktor berbasis penelitian yang mempengaruhi pembelajaran dengan pemahaman, termasuk mengakses pengetahuan sebelumnya (pada tahap keterlibatan), scaffolding (di setiap fase), membangun komunitas belajar (dalam persiapan untuk pelajaran dan sepanjang fase pelajaran 5E), transfer (terutama pada fase rumit), dan penilaian berkelanjutan (pada setiap fase).

Menurut Latifa, dkk (2017:66) model learning cycle $5 \mathrm{E}$ ini merupakan sarana yang kebih tepat dan efektif dalam pencapaian indikator-indikator kemampuan berpikir kritis. Hal pertama yang dilakukan yaitu memberikan permasalahan yang harus diselesaikan oleh peserta didik, jika peserta didik mengalami kesulitan, guru memberikan bimbingan secara bertahap sehingga kemampuan aktual yang dimiliki peserta didik menjadi kemampuan potensial. Petunjuk, peringatan, dorongan, menguraikan masalah ke dalam langkahlangkah pemecahan atau memberikan contoh merupakan bentuk bantuan yang diarahkan oleh guru (Chairani, 2015).

Dalam penelitian ini model pembelajaran tipe 5E merupakan tahapan yang juga terdapat dalam Lembar Kerja Peserta Didik (LKPD) berupa Engage (rumusan masalah), Explore (rencana kerja), Explain (hasil kerja), Elaborate (kesimpulan) dan Evaluate (evaluasi). Tahapan-tahapan tersebut menjadi tanggung jawab peserta didik untuk menyelesaikannya dalam bentuk proyek. Untuk menyelesaikan tahapan tersebut memerlukan praktek dalam kelas sehingga terciptanya transfer tanggung jawab yang awalnya ada pada guru kemudian beralih ke peserta didik sehingga pada akhirnya peserta didik memegang tanggung jawab penuh dalam menyelesaikan tugas secara mandiri tanpa bantuan dari guru lagi. Bantuan inilah yang disebut sebagai scaffolding.

Berdasarkan uraian di atas, penulis ingin melakukan penelitian tindakan kelas (PTK) di SMPN 1 Kota Jambi dengan menggunakan model pembelajaran inkuiri terbimbing berbasis scaffolding pada materi gerak kelas VIII. Scaffolding ini digunakan sebagai bantuan guru ke peserta didik sebagai transfer tanggung jawab dan memberikan bantuan berupa lembar kerja peserta didik (LKPD) agar dapat menunjang scaffolding dalam pembelajaran. Sehingga judul penelitian tindakan kelas ini yaitu "Penerapan Model Pembelajaran Inkuiri tipe 5E berbasis Scaffolding sebagai Transfer Tanggung Jawab pada kelas VIII I di SMPN 1 Kota Jambi".

\section{METODE PENELITIAN}

Penelitian ini dilakukan dengan mengembangkan Lembar Kerja Peserta Didik (LKPD) dan mempraktekkannya pada pembelajaran klasikal dalam bentuk Penelitian Tindakan Kelas (PTK)(Elliot, 1991). Penelitian tindakan kelas ini telah dilaksanakan di SMPN 1 Kota Jambi pada semester ganjil tahun pelajaran 20192020 yaitu dari tanggal 27 Agustus 2019 s/d 15 Oktober 2019. Subjek penelitian adalah siswa kelas VIII I berjumlah 32 orang yang terdiri dari 18 orang laki-laki dan 14 orang perempuan.

Penelitian ini dilaksanakan sebanyak tiga siklus dengan dengan karakeristik lingkungan belajar dan siswa yang memiliki ciri khas tersendiri. Metode pengumpulan data dalam penelitian tindakan kelas ini melalui 1) wawancara, 2) dokumen, 3) catatan lapangan, 4) observasi, 5) rekaman video. Metode 
pengumpulan data ini digunakan untuk memperoleh :

1. Data tindakan pendidik dalam menerapkan model inkuiri tipe $5 \mathrm{E}$ diperoleh berdasarkan lembar observasi kegiatan guru yang dilakukan oleh teman sejawat selaku observer pada mata pelajaran IPA. Data ini tertera dalam catatan harian penelitian tindakan kelas berdampingan dengan data tindakan peserta didik. Pada data ini terlihat transfer tanggung jawab dari guru ke peserta didik sehingga terdapat perubahan proses belajar yang dialami oleh peserta didik.

2. Data hasil observasi aktivitas proses sains peserta didik diperoleh melalui observasi yang dilakukan oleh teman sejawat selaku observer pada mata pelajaran IPA.

3. Data hasil penilaian keterampilan peserta didik diperoleh melalui instrumen penilaian keterampilan diskusi kelompok yang tertera pada LKPD dan praktik yang dilakukan oleh guru selaku peneliti. Total skor hasil observasi melalui instrumen penilaian keterampilan kelompok tiap tahapan inkuiri tipe 5E dalam Kurniasih (2014) yaitu :$$
\text { Nilai }=\frac{\text { Skor yang diperoleh }}{\text { Total Skor maksimum }}
$$
Pada penilaian keterampilan memperhatikan setiap tahapan LKPD yang mengacu pada sintak model pembelajaran inkuiri tipe $5 \mathrm{E}$ yaitu : rumusan masalah, rencana kerja, hasil kerja, kesimpulan dan evaluasi. Semua tahapan tersebut memiliki poin tertentu yang tercantum dalam instrumen keterampilan. Penjabaran dari intrumen penilaian keterampilan berdasarkan modul pengembangan instrumen kemendikbud tahun 2016. Penilaian dalam menyelesaikan LKPD merupakan penilaian proyek yang dimulai perencanaan, proses selama pengerjaan tugas, dan terhadap hasil akhir proyek. Penilaian ini tertuju pada penilaian terhadap hasil akhir proyek. Dengan demikian, guru perlu menentukan tahapan yang perlu dinilai seperti penyusunan

desain, pengumpulan data, analisis data, dan menyiapkan laporan tertulis. Pelaksanaan penilaian ini dapat menggunakan alat/instrument penilaian berupa daftar cek (checklist) ataupun skala rentang (rating scale) (Uno \& Koni, 2016).

4. Data hasil pembentukan kelompok belajar berdasarkan teman belajar yang dipilih langsung peserta didik melalui sosiometri dan sosiogram yang dilakukan oleh pendidik selaku peneliti.

\section{HASIL DAN PEMBAHASAN}

Penelitian dilaksanakan dengan menggunakan metode penelitian tindakan kelas. Saat pembelajaran berlangsung secara berkelanjutan dari satu siklus ke siklus berikutnya, guru memperbaiki tindakan pembelajaran inquiry terbimbing pada aspek menuntun dalam merumuskan masalah, menyusun rencana kerja, memproses hasil pengamatan, menyimpulkan dan melakukan evaluasi proyek. Perubahan tindakan guru dilakukan berdasarkan refleksi kemampuan siswa dalam melaksanakan kelima tahapan belajar tersebut. Adapun profile transfer tanggung jawab setiap kelompok yang dihasilkan diiustrasikan pada Gambar 1 s.d 6 berikut ini:

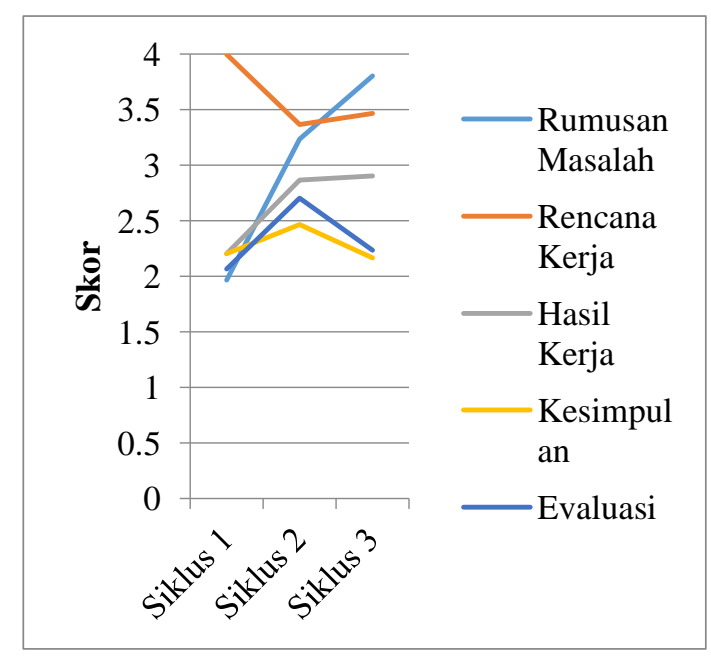

Gambar 1. Tahapan inkuiri kelompok I 
Pada Gambar 1 tahapan inquiry kelompok I, terjadi peningkatan pada rumusan masalah dan hasil kerja. Pada siklus I, anggota kelompok masih belum bisa merumuskan masalah karena belum menguasai materi pengantar. Hal ini berdampak juga pada rendahnya kemampuan kelompok menentukan hasil kerja, kesimpulan dan evaluasi. Rencana kerja pada siklus I masih sederhana dan bantuan di dalam LKPD masih tersedia dengan jelas sehingga anggota kelompok bisa memahami dan mengerjakan tahap ini. Pada siklus II, guru menyampaikan petunjuk penggunaan LKPD tiap tahapan. Anggota kelompok sudah memahami langkah-langkah pada masing-masing tahapan yang ada pada LKPD sehingga terjadi peningkatan pada rumusan masalah, hasil kerja, kesimpulan dan evaluasi namun bantuan berupa petunjuk sudah mulai berkurang sehingga anggota kelompok kesulitan menyusun rencana kerja. Salah satu anggota yang aktif bertanya menerima banyak bantuan pada setiap tahapan. Selain itu, kurangnya kolaborasi setiap anggota kelompok, beban tugas hanya diselesaikan oleh satu anggota kelompok sedangkan anggota lain hanya menyalin hasil kerja satu orang tersebut.

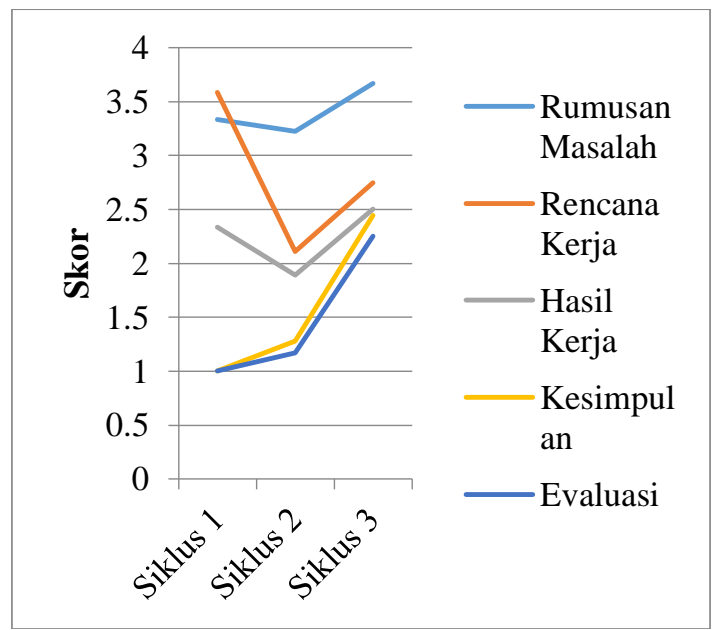

Gambar 2. Tahapan inkuiri kelompok II

Pada Gambar 2 tahapan inquiry kelompok II, hampir seluruh tahapan inquiry mengalami penurunan pada siklus II. Hal ini dikarenakan keterbatasan waktu (pengurangan jam pelajaran dari 40 menit/JP menjadi 20 menit/JP akibat bencana kabut asap). Peningkatan pada tahap kesimpulan dan evaluasi didukung dengan bantuan dari guru berupa arahan agar anggota kelompok bertanya dengan anggota yang sudah paham. Pada siklus III kolaborasi kelompok sudah semakin baik sehingga setiap tahapan mengalami peningkatan.

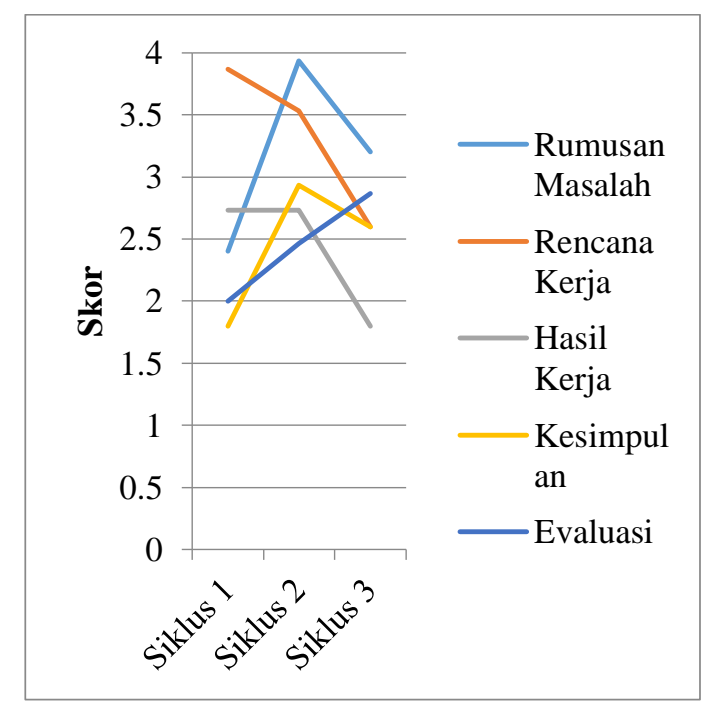

Gambar 3. Tahapan inkuiri kelompok III

Pada Gambar 3 tahapan inquiry kelompok III, terjadi peningkatan pada tahapan rumusan masalah, kesimpulan dan evaluasi. Hal ini di dukung dengan adanya bantuan dari guru berupa simulasi percobaan yang akan dilakukan. Sedangkan pada rencana kerja dan hasil kerja terjadi penurunan karena anggota kelompok tidak memahami LKPD dari segi membaca materi dan petunjuk setiap tahapan dalam LKPD. Pada siklus III, ketika bantuan sudah semakin berkurang, hampir seluruh tahapan inquiry mengalami penurunan. Hal ini menunjukkan bahwa anggota kelompok III masih memerlukan bantuan hingga akhir siklus. 


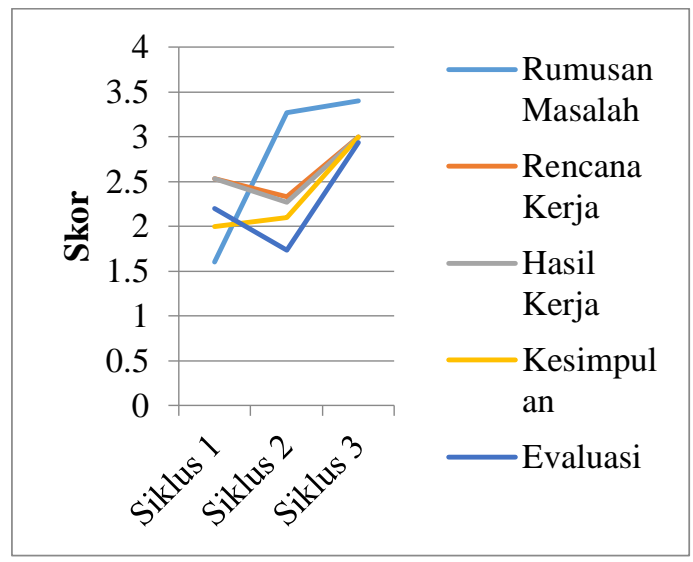

Gambar 4. Tahapan inkuiri kelompok IV

Pada Gambar 4 tahapan inquiry kelompok IV, hampir seluruh tahapan mengalami penurunan, hanya rumusan masalah yang mengalami peningkatan. Anggota kelompok sudah memahami tugas yang harus dikerjakan tetapi sebagian besar tahapan tidak dapat diselesaikan karena kurangnya waktu. Rumusan masalah masih memiliki waktu yang cukup sedangkan tahapan yang lain tidak dapat diselesaikan dengan baik karena adanya pengurangan jam pelajaran akibat bencana kabut asap. Kemudian terjadi peningkatan pada siklus III, anggota kelompok sudah memahami tiap tahapan pada LKPD dan sudah mau berkolaborasi antar anggota dalam satu kelompok maupun kelompok lain. Sehingga bantuan dari guru sudah berkurang. Hal ini menunjukkan kelompok IV sudah bertanggung jawab penuh dalam menyelesaikan tahapan inquiry bahkan tanpa bantuan dari guru.

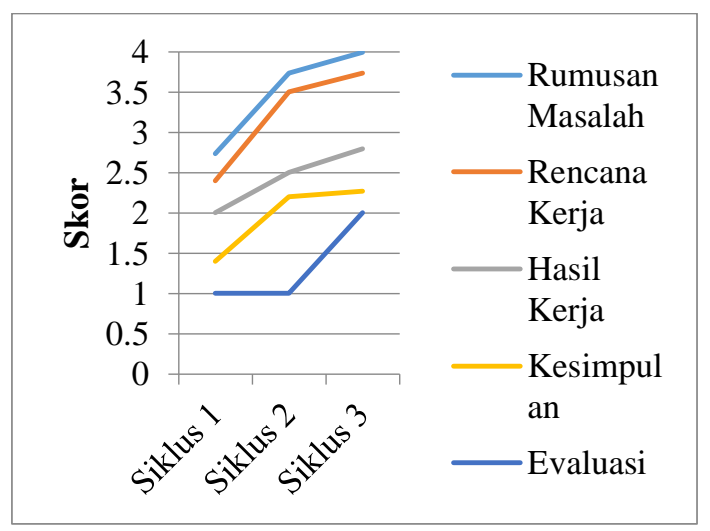

Gambar 5. Tahapan inkuiri kelompok V
Pada Gambar 5 tahapan inquiry kelompok $\mathrm{V}$, terjadi peningkatan pada setiap tahapan karena guru membimbing penyelesaian setiap tahapan kecuali pada tahapan evaluasi yang tidak terjadi peningkatan sama sekali sehingga anggota kelompok memerlukan penjelasan lebih rinci mengenai tahapan evaluasi pada siklus I dan II. Kemudian arahan dari guru agar setiap anggota kelompok berkontribusi dan berkolaborasi menyelesaikan tahapan inquiry. Sebagian anggota berkunjung ke kelompok lain untuk meminta petunjuk kepada anggota kelompok lain yang lebih memahami materi. Sehingga pada siklus III, kelompok V sudah tidak memerlukan bantuan dari guru dalam menyelesaikan setiap tahapan inkuiri.

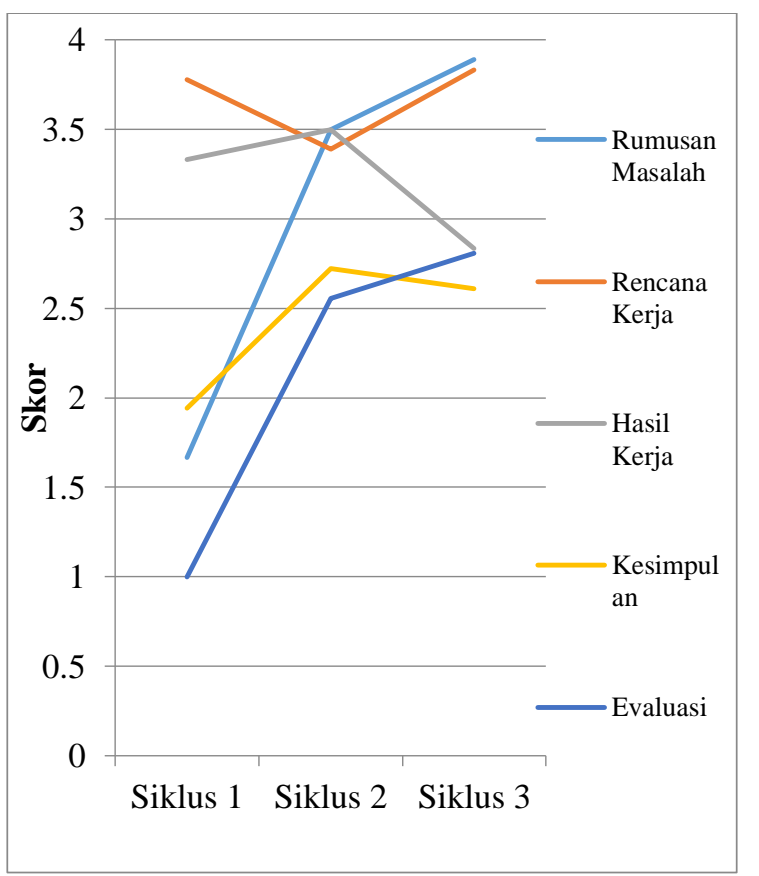

Gambar 6. Tahapan inkuiri kelompok VI

Pada Gambar 6 tahapan inquiry kelompok VI, terjadi peningkatan tahapan inkuiri dari siklus I ke siklus II karena guru memberikan bantuan ke anggota kelompok berupa penjelasan petunjuk penyelesaian tugas secara rinci dengan bahasa yang lebih mudah dipahami. Namun pada rencana kerja terjadi 
penurunan karena anggota kelompok VI kurang mampu menyusun kalimat yang utuh dan mudah dipahami. Pada siklus III, tahapan rumusan masalah, rencana kerja dan evaluasi mengalami peningkatan namun kurang signifikan. Kemudian pada tahapan hasil kerja dan kesimpulan mengalami penurunan karena bantuan berupa petunjuk dalam LKPD yang sudah berkurang. Hal ini menunjukkan bahwa kelompok VI masih membutuhkan bantuan verbal hingga akhir siklus.

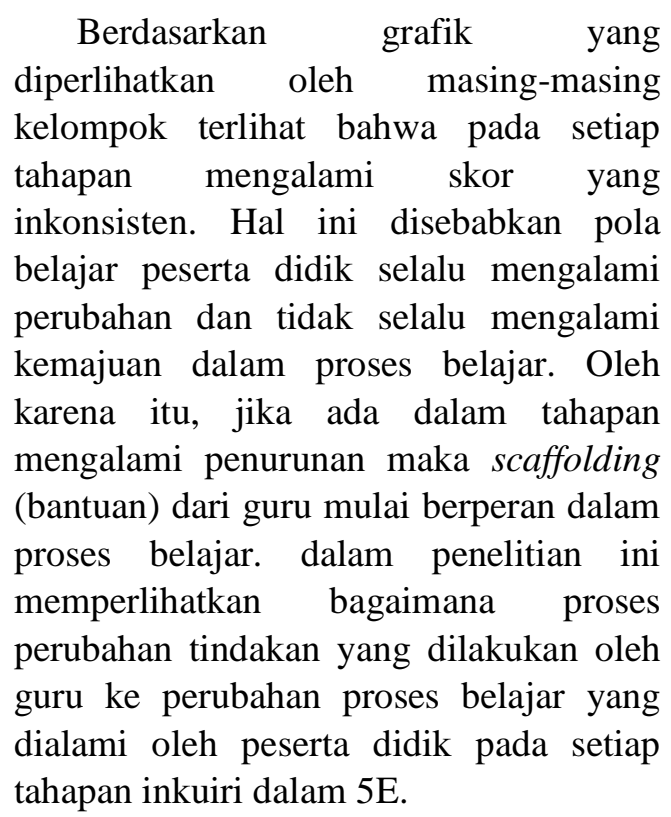

\section{KESIMPULAN}

Berdasarkan penelitian tindakan kelas yang telah dilaksanakan dapat disimpulkan model inkuiri tipe 5E berbasis scaffolding dapat membentuk transfer tanggung jawab yang terjadi antara guru dan peserta didik kelas VIII I di SMPN 1 Kota Jambi. Uraian profile transfer tanggung jawab yang terjadi pada setiap tahapan inkuiri, kelompok yang sudah mampu menyelesaikan tahapan sampai di akhir siklus tanpa bantuan dari guru yaitu kelompok II, IV dan V. Sedangkan kelompok yang masih membutuhkan bantuan dari guru sampai di akhir siklus yaitu kelompok I, II dan VI.

\section{DAFTAR PUSTAKA}

Chairani, Z. 2015. Scaffolding dalam Pembelajaran Matematika. Seminar Nasional Pendidikan Matematika STKIP PGRI 28 Jan 2015.

Contant, T., Tweed, A., Bass, J., \& Carin, A. (2018). Teaching Science-Through Inquiry Based Instruction. United State: Pearson Education.

Elliot, J., (1991). Action Research for Educational Change. Buckingham: Open University Press.

Latifa, B. R., Verawati, N. S., \& Harjono, A. (2017). Pengaruh Model Learning Cycle 5e (Engage, Explore, Explain, Elaboration, \& Evaluate) terhadap Kemampuan Berpikir. J. Pendidikan Fisika dan Teknologi, 3, 61-67.

Molenaar, I, van Boxtel, C.A.M., \& Sleegers, P.J.C., (2011), Metacognitive scaffolding in an innovative learning arrangement, Instructional Science, 39, 785-803.

Quintana, C., Reiser, B. J., Davis, E. A., Krajcik, J., Krajcik, E., Duncan, R. G., Kyza, E., Edelson, D., \& Edelson, E. (2004), A scaffolding design framework for software to support science inquiry, The Journal of The Learning Sciences, 13(3), 337-386.

Reigosa, C., \& Jiménez-Aleixandre, M. P., (2007), Scaffolded Problemsolving in the Physics and Chemistry Laboratory: Difficulties hindering students' assumption of responsibility, Inter. Journal of Science Education, 29(3), 307 - 329.

Shoimin, A. (2014). 68 Model Pembelajaran Inovatif dalam Kurikulum 2013. Yogyakarta: ArRuzz Media.

Uno, H. B., \& Koni, S. (2016). Assesment Pembelajaran. (D. Ispurwanti, Ed.) Jakarta: Bumi Aksara.

van de Pol, J., Volman, M. \& Beishuizen (2010), Scaffolding in TeacherStudent Interaction: A Decade of Research, Educational Psychology Review, 2 (3), pp 271-296. 